\title{
Readability Assessment of Online Patient Education Materials on Atrial Fibrillation
}

\author{
Emaad Siddiqui ${ }^{1}$, Aakash M. Shah ${ }^{2}$, Justin Sambol $^{2}$, Alfonso H. Waller ${ }^{3}$ \\ 1. Internal Medicine, New York University, New York, USA 2. Department of Cardiothoracic Surgery, Rutgers New \\ Jersey Medical School, Newark, USA 3. Department of Cardiovascular Disease, Rutgers New Jersey Medical School, \\ Newark, USA
}

Corresponding author: Emaad Siddiqui, emaadsidd@gmail.com

\begin{abstract}
Health literacy is emerging as an important factor for medical outcomes as more patients turn to the internet for information about their disease. However educational materials on complex conditions such as atrial fibrillation tend to still be esoteric and result in compromised patient autonomy. We add to the current literature by examining the reading level of websites of major healthcare intuitions and general medicine websites. An online Google search using the term "atrial fibrillation” was used to collect patient educational material from the first 20 academic health institutions (AHI) and 20 non-affiliated general medicine websites (GMW). The materials were assessed for readability using nine (9) tests from the analysis software Readability Studio (Oleander Software Solutions Ltd., Maharashtra, India). The patient education materials from the AHI and GMW websites were written at a college freshman reading grade level $(13.050 \pm 0.845)$ and high school junior year reading level $(11.64 \pm 0.789)$ respectively. The GMW tend to have a wider range of readability levels, and many were scored at the 6th-grade level. In conclusion, the readability levels of patient education materials on atrial fibrillation from both the AHI and GMW are well above the 6th-grade level recommended by the NIH and AMA, posing a risk to the patients' understanding of the materials. The high readability scores found across all websites and the differences between the groups have been attributed to the various goals and target audiences of the material.
\end{abstract}

Categories: Cardiology, Preventive Medicine, Public Health

Keywords: readability, cardiology, atrial fibrillation, online, google, patient education, materials

\section{Introduction}

Although the increased utilization of the internet has made healthcare information more accessible, poor healthcare literacy can be a major deterrent to patient autonomy [1,2]. Patient autonomy relies on the ability for patients to obtain and comprehend basic health information and services needed to make appropriate medical decisions [3]. This is not an easy task as medical terminology is nuanced and sometimes requires higher-level education to understand. As a result, many patients have little understanding of their diseases and even worse, little understanding of their treatment plan resulting in poor medical adherence, worse disease status, and early hospital readmission and mortality [4,5].

Received 06/11/2020 06/19/2020 Review ended 08/30/2020 Published 09/11/2020

(c) Copyright 2020 Siddiqui et al. This is an open access article distributed under the terms of the Creative Commons Attribution License CC-BY 4.0., which permits unrestricted use, distribution, and reproduction in any medium, provided the original author and source are credited.
This inadequate comprehension of healthcare material is compounded when acquiring information about complex diseases like atrial fibrillation, a disease that affects between 2 and 6 million people in the US [6]. Previous studies have demonstrated that $25 \%$ of the international adult population is unable to adequately explain atrial fibrillation, and these knowledge deficits are more prevalent in individuals with less education $[7,8]$. In addition to knowledge of the disease process, atrial fibrillation requires an adequate comprehension of multifaceted treatment plans, which require dangerous medications with the propensity to cause major bleeding $[9,10]$. Therefore, internet sources relaying uncomplicated and accurate information on atrial fibrillation would benefit millions of people and alleviate some of the burden faced by the healthcare industry due to a misguided understanding of atrial fibrillation treatment plans. Previous studies for cardiovascular disease have been developed to assess and evaluate education material [11]; however, few studies have analyzed the internet-based healthcare material for atrial fibrillation. Preliminary studies have shown that atrial fibrillation internet material requires a 10th-grade reading level, which is well above the recommended 6th-grade reading level [11,12].

As health care literacy is a fundamental component of patient education and patient shared-decision making, we hope to add to the current literature and to analyze the education level of major healthcare institutions as well as general medicine websites. Our evaluation will better delineate the current landscape of healthcare information and will uncover areas where healthcare information can be more appropriately presented.

\section{Materials And Methods}

An online search on Google was conducted on March 19, 2019 using the single key term "atrial fibrillation”. The search was limited to the United States and to articles written in English. Patient educational materials 


\section{Cureus}

were only included if they satisfied the following criteria: they were over 100 words; included a full overview of the disease including causes, risks, symptoms, diagnoses, and treatments; and were created specifically for patient use and information. Any articles or blogs were excluded from the analysis. The first 20 eligible academic institutions that were associated with a hospital were categorized as academic hospital institutions (AHI). The first 20 eligible general medicine websites that were not associated with any universities or hospitals were categorized as non-affiliated general medicine websites (NAGMW).

The materials were downloaded from the websites and reformatted into Microsoft Word (Microsoft Corp., Redmond, WA, USA). These texts were then edited to exclude any hyperlinks, advertisements, or extraneous information. The texts were also edited to reflect the original paragraph or bullet formats presented on the websites. The materials were then assessed for readability using the analysis software Readability Studio (Oleander Software Solutions Ltd., Maharashtra, India). A series of nine (9) previously validated scales for readability were tested on each study, including: Coleman Liau, Flesch Kincaid, FORCAST, Fry, Gunning Fog, Raygor Estimate, Simple Measure of Gobbledygook (SMOG), New Dale Chall, and Flesch Reading Ease (Table 1).

\begin{tabular}{|c|c|}
\hline Flesch Reading Ease & $206.835-(1.015 \times C)$ \\
\hline FORCAST & $20-(E \div 10)$ \\
\hline Fry & $\begin{array}{l}100 \text { word passage selected from text. \# of sentences and \# of syllables in passage calculated. Assessed on } \\
\text { graph and readability measured }\end{array}$ \\
\hline Gunning Fog & $0.4 \times((D \div F)+100(G \div D))$ \\
\hline SMOG & $1.043 \times \sqrt{ }(\mathrm{H} \times(30 / \mathrm{F}))+3.1291$ \\
\hline
\end{tabular}

\section{TABLE 1: Readability Assessment Scales}

The letters designate the following: A = average \# of letters per 100 words; $\mathrm{B}=$ average \# of sentences per 100 word; $\mathrm{C}=$ number of "easy" words within sample; $D=$ average number of words per sentences; $E=$ number of single syllable words in a 150 -word sample; $F=$ average number of sentences; $\mathrm{G}=$ average number of words with 3 or more syllables; $\mathrm{H}=$ number of polysyllabic words in sample; $\mathrm{I}=$ percentage of difficult words in text.

SMOG $=$ Simple Measure of Gobbledygook

The mean readability grade and age levels were computed for each of the websites. The mean overall reading grade level was calculated for both categories and compared using statistical analysis in Statistical Package for the Social Sciences (SPSS) (IBM Corp, Armonk, NY, USA). The data was treated as nonparametric and compared with a simple independent samples T-test with significance set at $\mathrm{p}<0.05$.

\section{Results}

A total of 20 academic hospital institutions (AHI) and 20 non-affiliated general medicine websites (NAGMW) were identified in this study. The patient education materials from the academic hospital institutions were written at a college freshman reading grade level (13.050 $\pm 0.845 \mathrm{CL})$. Material published by University of North Carolina at Chapel Hill, University of Chicago, and Emory University received the highest scores on these readability scales with mean grade levels of 16.2, 15.7, and 15.6 respectively. Robert Wood Johnson (RWJ) and the University of California San Francisco required the lowest reading levels on average, with mean grade levels of 10 and 10.3 respectively. Three institutions, including RWJ, University of Maryland, and Temple, failed the assessment by the Fry and Raygor Estimate readability scales for having too many $6+$ syllable words and long sentences in their texts (Table 2 and Figure $)$. 


\section{Cureus}

\begin{tabular}{|c|c|c|c|c|c|c|c|c|c|c|c|}
\hline $\begin{array}{l}\text { General Medicine } \\
\text { Website }\end{array}$ & $\begin{array}{l}\text { Coleman } \\
\text { Liau }\end{array}$ & $\begin{array}{l}\text { Flesch } \\
\text { Kinaud }\end{array}$ & FORCAST & Fry & $\begin{array}{l}\text { Gunning } \\
\text { Fog }\end{array}$ & $\begin{array}{l}\text { Raygor } \\
\text { Estimate }\end{array}$ & SMOG & $\begin{array}{l}\text { New Dale } \\
\text { Chall }\end{array}$ & $\begin{array}{l}\text { Flesch Reading } \\
\text { Ease }\end{array}$ & Mean & $\begin{array}{l}\text { Mean Reader } \\
\text { Age }\end{array}$ \\
\hline $\mathrm{AHA}^{*}$ & 11.6 & 9.8 & 10.8 & 11 & 11.8 & 11 & 12.3 & 11 to 12 & 53 & 11.2 & 16.3 \\
\hline Web MD & 8.6 & 6.3 & 9.4 & 7 & 8.4 & 6 & 9.8 & 5 to 6 & 71 & 7.8 & 12.8 \\
\hline Heart Rhythm & 11.3 & 9.9 & 10.3 & 11 & 12 & 11 & 12.6 & 11 to 12 & 54 & 11.1 & 16.4 \\
\hline $\mathrm{NIH} \dagger$ & 12.4 & 10.6 & 11 & 13 & 13.5 & 12 & 13.3 & 11 to 12 & 48 & 12.2 & 17.4 \\
\hline Cardio Smart & 10.5 & 8.2 & 10.2 & 9 & 9.5 & 8 & 10.9 & 7 to 18 & 62 & 9.2 & 14.4 \\
\hline Medtronic & 10.6 & 7.3 & 11 & & 10.7 & & 10.2 & 9 to 10 & 56 & 9.9 & 15.1 \\
\hline Med News Today & 11.3 & 10.3 & 10.8 & 11 & 11.7 & 11 & 12.7 & 9 to 10 & 52 & 11 & 16.2 \\
\hline Healthline & 11.9 & 10 & 11.1 & 12 & 12.6 & 11 & 12.6 & 11 to 12 & 50 & 11.6 & 16.8 \\
\hline Medline & 12.8 & 11.4 & 10.9 & 15 & 14.1 & 12 & 14.2 & 13 to 15 & 44 & 13.1 & 18.3 \\
\hline OnHealth & 11.8 & 10.5 & 10.6 & 12 & 12.6 & 11 & 13 & 11 to 12 & 50 & 11.6 & 16.8 \\
\hline EMedicineHealth & 14.2 & 13 & 11.7 & 17 & 15.4 & 17 & 15.2 & 13 to 15 & 34 & 14.7 & 20 \\
\hline StopTheClot & 11 & 9.5 & 10.2 & 10 & 10.9 & 10 & 12.2 & 11 to 12 & 58 & 10.7 & 15.9 \\
\hline StopAfib & 11.3 & 10.3 & 10.6 & 12 & 12.7 & 10 & 13 & 9 to 10 & 51 & 11.2 & 16.4 \\
\hline Thrombosis Adviser & 11.5 & 11.9 & 10.5 & 14 & 13.4 & 11 & 14.2 & 11 to 12 & 46 & 12.3 & 17.4 \\
\hline Merck Manual & 13.2 & 12.3 & 11.4 & 17 & 15 & 13 & 14.6 & 13 to 15 & 38 & 13.8 & 19.1 \\
\hline VeryWellHealth & 13.9 & 13.1 & 11.6 & 17 & 15.6 & 17 & 15.2 & 13 to 15 & 34 & 14.7 & 19.9 \\
\hline HeartAndStroke & 11.4 & 9.3 & 10.8 & & 11.3 & 10 & 12 & 9 to 10 & 52 & 10.6 & 15.9 \\
\hline SecondsCount & 11.6 & 10.5 & 10.6 & 12 & 12.7 & 11 & 13.1 & 11 to 12 & 51 & 11.6 & 16.8 \\
\hline EverydayHealth & 11.4 & 11.3 & 10.8 & 12 & 13.6 & 11 & 13.5 & 11 to 12 & 50 & 11.9 & 17.1 \\
\hline Texas Heart & 12.9 & 10.7 & 11.2 & 16 & 12.6 & 13 & 13.1 & 11 to 12 & 45 & 12.6 & 17.8 \\
\hline
\end{tabular}

TABLE 2: Readability Analysis of Education Materials, by Non-Affiliated General Medicine Websites

*American Heart Association; †National Institute of Health; SMOG = Simple Measure of Gobbledygook

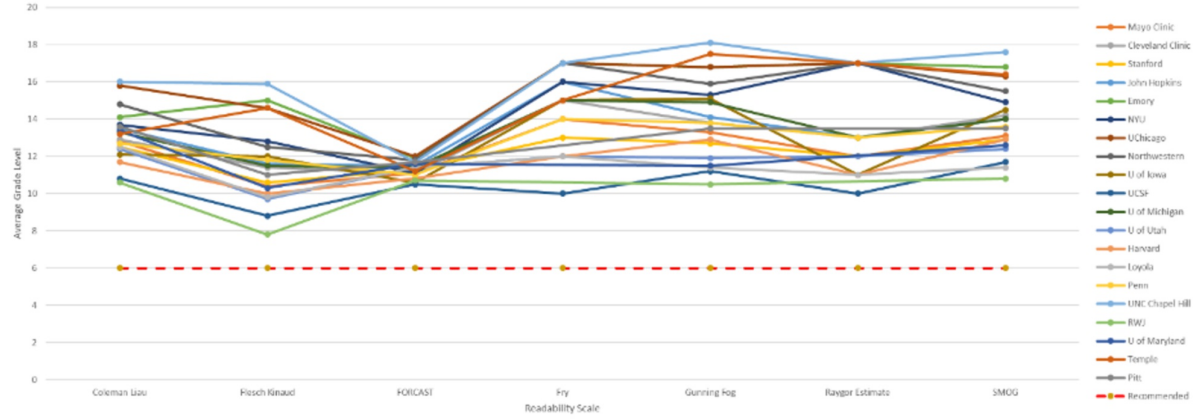

FIGURE 1: Graphical representation of the individual readability scores for each academic institution

The "recommended" line marks the 6th grade reading level recommended by the American Heart Association (AMA) and National Institute for Health (NIH). NYU = New York University; UChicago = University of Chicago; UCSF = University of California, San Francisco; RWJ = Robert Wood Johnson. 


\section{Cureus}

For the non-academic medicine websites, the patient education materials were written at a high school junior year reading level $(11.64 \pm 0.789 \mathrm{CL})$. Online information from VeryWellHealth and eMedicine health were written at the highest grade level with a mean of 14.7. WebMD's material required the lowest reading level of all the websites, with a mean grade level of 7.8. In addition, the website scored at the recommended 6th-grade reading level on two of the readability scales, the Flesch Kincaid and Raygor Estimate. Only one website, Medtronic, failed to be assessed by the Fry or Raygor Estimate readability scales for having too many 6+ syllable words and long sentences (Table 3 and Figure 2).

\begin{tabular}{|c|c|c|c|c|c|c|c|c|c|c|c|}
\hline $\begin{array}{l}\text { Academic } \\
\text { Institution }\end{array}$ & $\begin{array}{l}\text { Coleman } \\
\text { Liau }\end{array}$ & $\begin{array}{l}\text { Flesch } \\
\text { Kincaid }\end{array}$ & FORCAST & Fry & $\begin{array}{l}\text { Gunning } \\
\text { Fog }\end{array}$ & $\begin{array}{l}\text { Raygor } \\
\text { Estimate }\end{array}$ & SMOG & $\begin{array}{l}\text { New Dale } \\
\text { Chall }\end{array}$ & $\begin{array}{l}\text { Flesch Reading } \\
\text { Ease }\end{array}$ & Mean & $\begin{array}{l}\text { Mean Reader } \\
\text { Age }\end{array}$ \\
\hline Mayo Clinic & 12.8 & 10.4 & 11.1 & 14 & 13.3 & 12 & 13.1 & 11 to 12 & 47 & 12.3 & 17.6 \\
\hline Cleveland Clinic & 12.9 & 11.4 & 11.1 & 15 & 13.8 & 13 & 14.2 & 11 to 12 & 43 & 12.9 & 18.1 \\
\hline Stanford & 12.5 & 10.6 & 11.3 & 13 & 12.7 & 12 & 12.9 & 11 to 12 & 48 & 12.1 & 17.2 \\
\hline John Hopkins & 13.5 & 11.6 & 11.5 & 16 & 14.1 & 13 & 14 & 13 to 15 & 41 & 13.5 & 18.8 \\
\hline Emory & 14.1 & 15 & 11.9 & 17 & 16.8 & 17 & 16.8 & $16+$ & 27 & 15.6 & 20.8 \\
\hline NYU* & 13.7 & 12.8 & 11.1 & 16 & 15.3 & 17 & 14.9 & 13 to 15 & 38 & 14.4 & 19.5 \\
\hline Univ of Chicago & 15.8 & 14.6 & 12 & 17 & 16.8 & 17 & 16.3 & $16+$ & 26 & 15.7 & 20.9 \\
\hline Northwestern & 14.8 & 12.5 & 11.8 & 17 & 15.9 & 17 & 15.5 & $16+$ & 35 & 15.1 & 20.1 \\
\hline Univ of lowa & 12.1 & 12 & 10.6 & 15 & 15.1 & 11 & 14.5 & 11 to 12 & 42 & 12.7 & 18.1 \\
\hline Univ of CSF† & 10.8 & 8.8 & 10.5 & 10 & 11.2 & 10 & 11.7 & 9 to 10 & 58 & 10.3 & 15.4 \\
\hline U of Michigan & 13.3 & 11.5 & 11.4 & 15 & 14.9 & 13 & 14 & 13 to 15 & 43 & 13.4 & 18.6 \\
\hline Univ of Utah & 12.4 & 9.7 & 11.4 & 12 & 11.9 & 12 & 12.4 & 9 to 10 & 50 & 11.4 & 16.6 \\
\hline Harvard & 11.7 & 10 & 10.8 & 12 & 12.9 & 11 & 12.9 & 11 to 12 & 50 & 11.6 & 16.7 \\
\hline Loyola & 12.5 & 9.8 & 11.4 & 12 & 11.4 & 11 & 11.4 & 11 to 12 & 49 & 11.4 & 16.6 \\
\hline Penn & 12.7 & 11.8 & 11 & 14 & 13.8 & 13 & 13.6 & 13 to 15 & 44 & 13 & 18.1 \\
\hline UNC Chapel Hill & 16 & 15.9 & 11.7 & 17 & 18.1 & 17 & 17.6 & $16+$ & 21 & 16.2 & 21.4 \\
\hline RWJ‡ & 10.6 & 7.8 & 10.7 & Failed & 10.5 & Failed & 10.8 & 9 to 10 & 60 & 10 & 14.9 \\
\hline $\mathrm{U}$ of Maryland & 13.4 & 10.3 & 11.6 & Failed & 11.5 & Failed & 12.6 & 11 to 12 & 45 & 11.8 & 16.6 \\
\hline Temple & 13.2 & 14.6 & 11.2 & 15 & 17.5 & 17 & 16.4 & $16+$ & 35 & 15.1 & 20.4 \\
\hline Pitt & 13.6 & 11 & 11.7 & Failed & 13.5 & Failed & 13.5 & 11 to 12 & 41 & 12.5 & 17.6 \\
\hline
\end{tabular}

\section{TABLE 3: Readability Analysis of Education Materials, by Academic Institution}

*New York University; †University of California: San Francisco; ‡Robert Wood Johnson

$\mathrm{SMOG}=$ Simple Measure of Gobbledygook 


\section{Cureus}

FIGURE 2: Graphical representation of the individual readability scores of each academic institution.

The "recommended" line marks the 6th grade reading level recommended by the AMA and NIH. AHA = American Heart Association; NIH = National Institute of Health.

Overall, the materials produced by the general medicine websites were significantly easier to read than those produced by the academic hospital institutions (11.64 vs 13.050 mean grade level, $p$ value 0.015 ) (Table 4). The range of average grade levels was larger for the NAGMW group, and the AHI group showed a more even distribution for its scores (Figure 3). In both groups, the FORCAST readability scale produced the most precise results, with all scores falling within two to three grade levels from each other within each group. The Fry, Gunning Fog, and Raygor Estimates scales displayed the most variability in the scores and highlighted most of the differences in readability levels within the groups, especially with the general medicine websites (Figure 4 and Figure 5).

\begin{tabular}{|l|l|l|}
\hline & Academic & General \\
\hline & Institution & Medicine \\
\hline Average Readability Level & $13.050 \pm 0.845$ & $11.64 \pm 0.789$ \\
\hline
\end{tabular}

TABLE 4: Comparison of Average Readability Level of Patient Education Materials

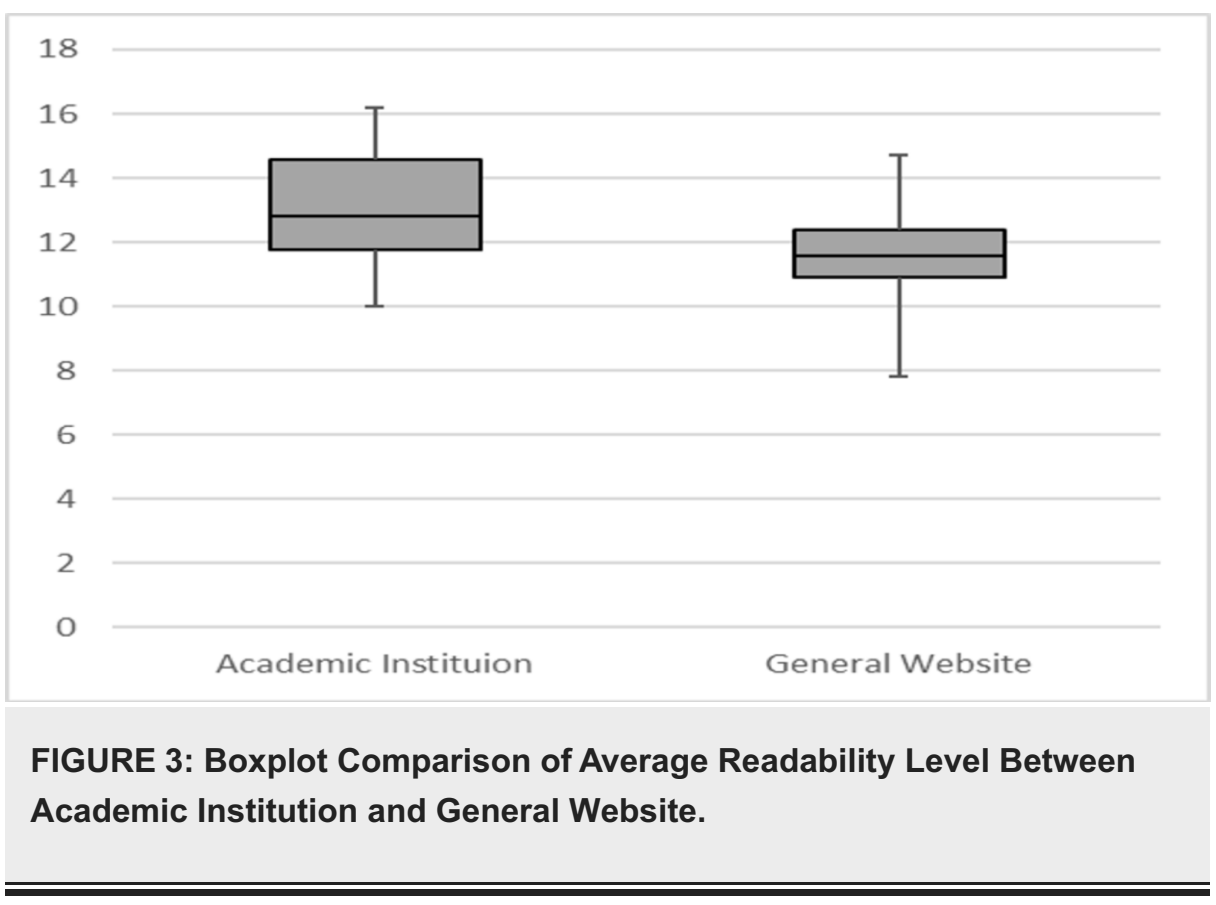




\section{Cureus}
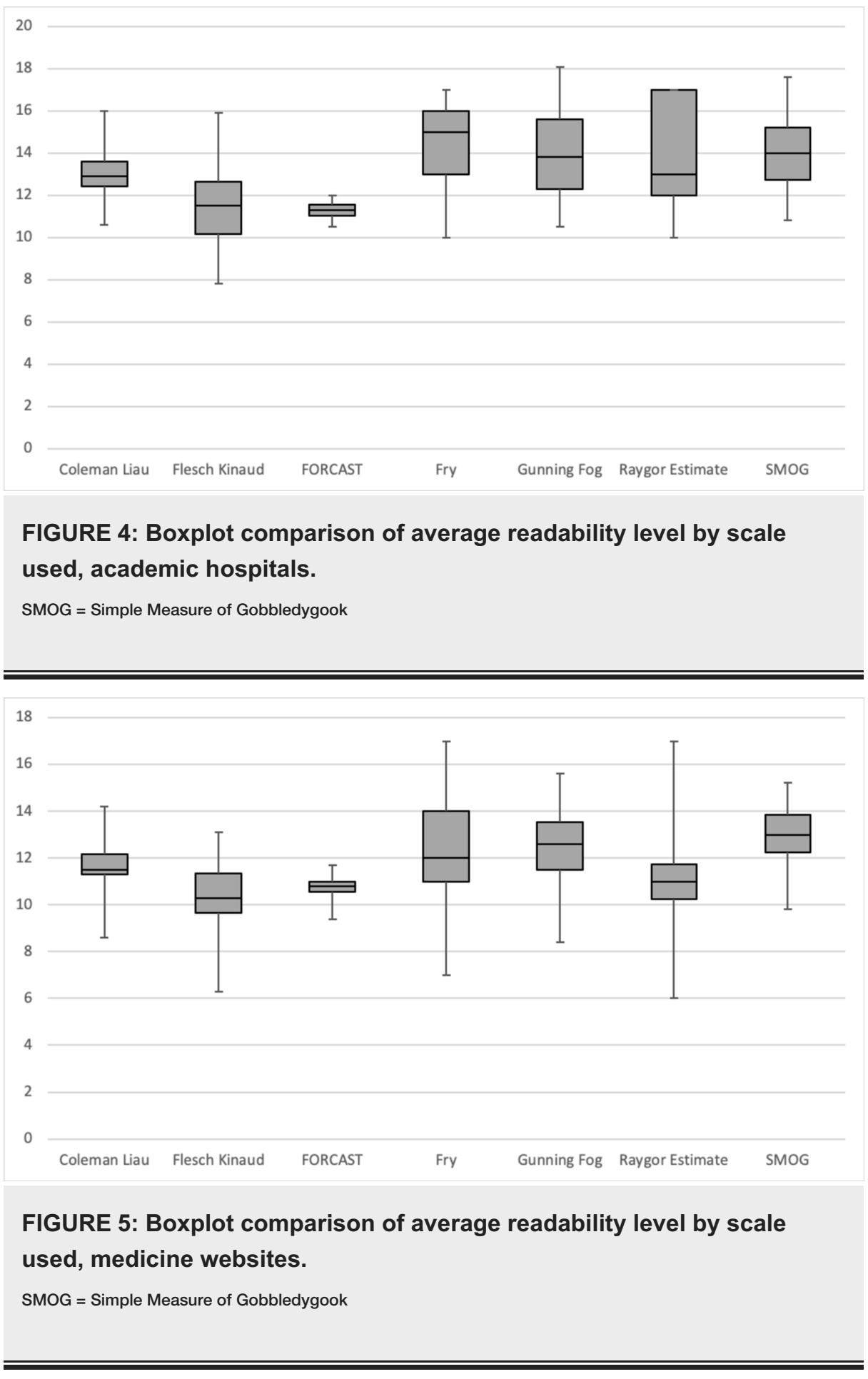

\section{Discussion}

Health literacy is quickly becoming a key subject of analysis by the medical community as numerous studies have emerged revealing the adverse effect of poor health literacy on medical outcomes $[13,14]$. It is defined by the Institute of Medicine as "the degree to which individuals have the capacity to obtain, process, and understand basic health information and services needed to make appropriate health decisions" [15]. Therefore, information received by patients has a profound effect on their medical decisions, and in order for patients to control their own healthcare, healthcare-related information must be both informative and comprehensible.

An important part of this health information is the ease at which the text can be read and understood, otherwise known as its readability. In the United States, it is typically measured by school grade levels, ranging from kindergarten to post-graduate reading proficiency. Many tests have been developed to assess readability of documents by analyzing components of the text including the complexity of the words, length of sentences, and use of high-level jargon (Table 1). Recent surveys show that only $12 \%$ of Americans have 
A 2018 survey conducted by the US Census Bureau determined that $99 \%$ of the US population can read at a 5th- to 6th-grade level [18]. Therefore, many institutions including the AMA and NIH have recommended that patient educational materials be written at a 6th-grade reading level to ensure that the majority of the population will be able to comprehend the material $[19,20]$.

As the use of the internet has increased in the last decade, more patients are turning to Google to access these educational materials. Nearly $60 \%$ of Americans say they use the internet as their first choice to get medical information, and about $80 \%$ of those individuals will start with a simple Google search of their disease [21]. This exposes patients to a wide variety of websites with medical information from many different sources. Although the information presented in the materials must be accurate, it should also be easily understandable as studies show that misinterpretation of online health information can lead to negative healthcare outcomes [22].

Atrial fibrillation is one of the more complicated diseases of the heart as it requires an understanding of electrophysiology, cardiovascular mechanics, and its relation to stroke risk. A variety of tests and treatments are available for patients and can often be confusing for newly diagnosed patients, especially since most procedures involve electrical and chemical ablation [11]. A previous survey has shown that nearly $50 \%$ of physicians felt that their patients were unable to explain their diagnosis sufficiently [7]. Other surveys also demonstrate that many of the deficits in knowledge about treatment of atrial fibrillation are more pronounced in patients with lower educational backgrounds and poor health literacy [8,23]. Educational interventions have proven in the past to increase patients' knowledge about atrial fibrillation [24], and therefore all sources of patient education should be scrutinized including materials from online websites.

This study reveals that materials written by both academic institutions and medicine websites required reading levels well above the recommendations made by most public health institutions. This finding is consistent with similar studies conducted in different specialties [25]. Patients with low levels of literacy will most likely have a difficult time understanding these websites. The internet allows the patient to have greater autonomy over their care and therefore, they may choose what resources they use to access educational materials. This may lead to the patient receiving confusing and inaccurate information about their disease which may adversely affect their medical decision-making capacity [26].

Materials from the general medicine websites were significantly easier to read than ones from the academic institutions, which was also found in a similar analysis on online education for pancreatic cancer [27]. The main difference in these medical websites from the academic hospital institutions is most likely the use of medical terminology. The nine readability scales calculate the scores based on the number and complexity of the sentences, words, and syllables used in the text. Since most of the texts between the two groups were similar in length, the amount of medical jargon likely had the largest impact on the readability levels of these texts. A previous readability analysis demonstrated that replacement of the medical terminology with simpler words reduced the required reading level to more acceptable levels for nearly all websites examined in the study [28]. Without sacrificing the accuracy of the materials, reducing the amount of medical jargon should be a focus when reviewing these texts [29].

The authors recognize that with atrial fibrillation, many of these polysyllable words are unavoidable including terms related to electrophysiology. Therefore, other areas for the improvement of readability should be considered. Many of the websites in this study contained videos, images, and charts that were not considered in the analysis. The use of multimedia may not alter the readability level of the text but may help patients better understand the information [30]. This may be particularly used for atrial fibrillation as it involves visualizing the abnormal electrical rhythm and its path in the heart. In addition, many guides have been published specifically to improve healthcare materials. Recommendations from these websites include limiting sentences to 8-10 words, paragraphs to 3-5 sentences, and using more active phrases rather than passive ones [19].

Many of the limitations of this study are inherent to the readability scales used in the analysis. They only measure the complexity of the words, sentences, and paragraphs of the text, but not the specific format or arrangements of the material. As noted earlier, they also do not measure the use of multimedia which may supplement the reading material. While the scales do provide the best quantitative measure and allow for comparison of different materials, analysis of multimedia in tandem with the reading scales would give a better picture of the readability of the website. In addition, while some websites may be easier to read it is important to also conduct an analysis of the accuracy of the material presented to ensure that the information the patients receive is correct. This study focused on websites from academic institutions and non-affiliated general medicine websites, and while these categories encompassed most of the websites on the first 10 pages of the Google search, there are other websites from hospital networks and independent physicians that appeared and can be analyzed in future studies. The word atrial fibrillation may inherently inflate the reading level. The word can be replaced in the future with "this disease" or "AF" or something similar. We mitigated this issue by using multilpe reading scale metrics that focus on different components of the material. However, we maintained the word in our analysis because other studies have shown that 
complex words make text esoteric because of their complex meaning and their length, syllable count, and familiarity. Therefore, the word atrial fibrillation may be an important component when measuring readability. Future sources written about atrial fibrillation should work to use replacement words as they may make reading the information easier helping patients better understand the disease and treatment plan.

\section{Conclusions}

Patient education materials on atrial fibrillation from academic hospital institutions and non-affiliated general medicine websites are written at grade levels higher than the 6th-grade level recommended by many major public health institutions, including the NIH and the AMA. The increasing number of patients who refer to these materials may not be able to comprehend these texts and may be less likely to make informed decisions about their medical care. In addition, materials from general medicine websites are significantly easier to read than ones from academic institutions, indicating that the selection of materials is important. Future interventions should place emphasis on the readability of online patient education materials to improve outcomes for common and complex cardiovascular diseases.

\section{Additional Information \\ Disclosures}

Human subjects: All authors have confirmed that this study did not involve human participants or tissue. Animal subjects: All authors have confirmed that this study did not involve animal subjects or tissue. Conflicts of interest: In compliance with the ICMJE uniform disclosure form, all authors declare the following: Payment/services info: All authors have declared that no financial support was received from any organization for the submitted work. Financial relationships: All authors have declared that they have no financial relationships at present or within the previous three years with any organizations that might have an interest in the submitted work. Other relationships: All authors have declared that there are no other relationships or activities that could appear to have influenced the submitted work.

\section{References}

1. Kim C, Gupta R, Shah A, Madill E, Prabhu AV, Agarwal N: Digital footprint of neurological surgeons. World Neurosurg. 2018, 113:172-178. doi.org/10.1016/j.wneu.2018.01.210

2. Joseph-Williams N, Elwyn G, Edwards A: Knowledge is not power for patients: a systematic review and thematic synthesis of patient-reported barriers and facilitators to shared decision making. Patient Educ Couns. 2014, 94:291-309. doi.org/10.1016/j.pec.2013.10.031

3. Haun JN, Valerio MA, McCormack LA, Sorensen K, Paasche-Orlow MK: Health literacy measurement: an inventory and descriptive summary of 51 instruments. J Health Commun. 2014, 2:302-33. doi.org/10.1080/10810730.2014.936571

4. Bostock S, Steptoe A: Association between low functional health literacy and mortality in older adults: longitudinal cohort study. BMJ. 2012, 344:1602. doi.org/10.1136/bmj.e1602

5. Baker DW, Wolf MS, Feinglass J, Thompson JA, Gazmararian JA, Huang J: Health literacy and mortality among elderly persons. Arch Intern Med. 2007, 167:1503-9. 10.1001/archinte.167.14.1503

6. January CT, Wann LS, Alpert JS: 2014 AHA/ACC/HRS guideline for the management of patients with atrial fibrillation: a report of the American College of Cardiology/American Heart Association Task Force on Practice Guidelines and the Heart Rhythm Society. J Am Coll Cardiol. 2014, 64:1-76. 10.1016/j.jacc.2014.03.022

7. Aliot E, Breithardt G, Brugada J: An international survey of physician and patient understanding, perception, and attitudes to atrial fibrillation and its contribution to cardiovascular disease morbidity and mortality. Europace. 2010, 12:626-33. 10.1093/europace/euq109

8. Xu W, Sun G, Lin Z : Knowledge, attitude, and behavior in patients with atrial fibrillation undergoing radiofrequency catheter ablation. J Interv Card Electrophysiol. 2010, 28:199-207. 10.1007/s10840-010-94962

9. Goli NM, Thompson T, Sears SF: Educational attainment is associated with atrial fibrillation symptom severity. Pacing Clin Electrophysiol. 2012, 35:1090-6. 10.1111/j.1540-8159.2012.03482.x

10. Smith MB, Christensen N, Wang S: Warfarin knowledge in patients with atrial fibrillation: implications for safety, efficacy, and education strategies. Cardiology. 2010, 116:61-9. 10.1159/000314936

11. Aronis KN, Edgar B, Lin W, Martins MAP, Paasche-Orlow MK, Magnani JW: Health literacy and atrial fibrillation: relevance and future directions for patient-centred care. Eur Cardiol. 2017, 12:52-7. 10.15420/ecr.2017:2:2

12. Weiss BD, Coyne C: Communicating with patients who cannot read . N Engl J Med. 1997, 337:272-4. 10.1056/NEJM199707243370411

13. Jovanic M, Zdravkovic M, Stanisavljevic D, Jovic Vranes A: Exploring the importance of health literacy for the quality of life in patients with heart failure. Int J Environ Res Public Health. 2018, 15:10.3390/ijerph15081761

14. Palumbo R: Discussing the effects of poor health literacy on patients facing HIV: a narrative literature review. Int J Health Policy Manag. 2015, 4:417-30. 10.15171/ijhpm.2015.95

15. Institute of Medicine: Health Literacy: A Prescription to End Confusion. Nielsen-Bohlman L, Panzer AM, Kindig DA (ed): The National Academies Press, Washington D.C.; 2004. 10.17226/10883

16. America's Health Literacy: Why We Need Accessible Health Information . (2008). https://www.cdc.gov/healthliteracy/learn/Resources.html.

17. Cutilli CC, Bennett IM: Understanding the health literacy of America: results of the National Assessment of Adult Literacy. Orthop Nurs. 2009, 28:27-32. 
18. Current population survey data on educational attainment of the population 18 years and over . (2018). https://www.census.gov/data/tables/2018/demo/education-attainment/cps-detailed-tables.html.

19. How to Write Easy to Read Health Materials: Medline Plus . (2018).

https://www.scribd.com/document/261199628/How-to-Write-Easy-To-Read-Health-Materials-MedlinePlus.

20. Walsh TM, Volsko TA: Readability assessment of internet-based consumer health information. Respir Care. 2008, 53:1310-5.

21. Fox S, Duggan, M: Health Online. Pew Research Center, Washington, D.C.; 2013.

22. El Sherif R, Pluye P, Thoer C, Rodriguez C: Reducing negative outcomes of online consumer health information: qualitative interpretive study with clinicians, librarians, and consumers. J Med Internet Res. 2018, 20:169. 10.2196/jmir.9326

23. Hendriks JM, Crijns HJ, Tieleman RG, Vrijhoef HJ: The atrial fibrillation knowledge scale: development, validation and results. Int J Cardiol. 2013, 168:1422-8. 10.1016/j.ijcard.2012.12.047

24. McCabe PJ, Schad S, Hampton A, Holland DE: Knowledge and self-management behaviors of patients with recently detected atrial fibrillation. Heart Lung. 2008, 37:79-90. 10.1016/j.hrtlng.2007.02.006

25. Gupta R, Adeeb N, Griessenauer CJ: Evaluating the complexity of online patient education materials about brain aneurysms published by major academic institutions. J Neurosurg. 2017, 127:278-283. 10.3171/2016.5.JNS16793

26. Rubin MA: The collaborative autonomy model of medical decision-making. Neurocrit Care. 2014, 20:311-8. 10.1007/s12028-013-9922-2

27. Storino A, Castillo-Angeles M, Watkins AA: Assessing the accuracy and readability of online health information for patients with pancreatic cancer. JAMA Surg. 2016, 151:831-7. 10.1001/jamasurg.2016.0730

28. Meillier A, Patel S: Readability of healthcare literature for gastroparesis and evaluation of medical terminology in reading difficulty. Gastroenterology Res. 2017, 10:1-5. 10.14740/gr746w

29. Sand-Jecklin K: The impact of medical terminology on readability of patient education materials . J Community Health Nurs. 2007, 24:119-29. 10.1080/07370010701316254

30. Doak CC, Doak LG, Root JH: Teaching Patients With Low Literacy Skills. Lippincott Williams \& Wilkins, Philadelphia; 1985. 